\title{
Social Skills Deficits in Autism: A Study among Students with Austim Spectrum Disorder in Inclusive Classrooms
}

\author{
Kee Jiar Yeo, Kie Yin Teng* \\ Faculty of Education, Universiti Teknologi Malaysia, Malaysia
}

Copyright $(2015$ by authors, all rights reserved. Authors agree that this article remains permanently open access under the terms of the Creative Commons Attribution License 4.0 International License

\begin{abstract}
Students with Autism Spectrum Disorder (ASD) who lack of social skills have been hindered from being included in IE classrooms. The purpose of this study was to identify the most frequently occurring social skills deficits area among students with ASD in IE classrooms so that the mainstream teachers will be ready and well prepared to cater to their special educational needs (SEN) accordingly in order to yield more effective educational outcomes. A total of 34 teachers in three schools with inclusive classrooms in Johor state, Malaysia were involved in this study. The instrument used in the current study was adapted from TRIAD Social Skills Assessment (TSSA) by Vanderbilt Kennedy Center. The instrument was adapted and consisting of a 41-items survey form which assess the knowledge and skills of students with ASD in three areas, namely cognitive, behavioral and affective. The findings showed the most observed social skills deficits fall under behavioral and affective areas. Comparison of the three areas in social skills using repeated measures analyses indicated that there was a significant difference among the scores of three areas among the students with ASD. The implications of practice were discussed.
\end{abstract}

Keywords Social Skills, Autism Spectrum Disorder, Inclusive Education

\section{Introduction}

Autism spectrum disorders (ASD) is characterized by deficits in two core domains: deficits in social communication and social interaction; restricted repetitive patterns of behavior, interests and activities [1]. Their social skills deficits are characterized by poor eye contact, lack of joint attention, pedantic or odd speech patterns, difficulty both initiating and maintaining conversations, lack of social problem-solving ability, lack of empathy, and difficulties interpreting body language [2]. Students with ASD are having difficulties in developing their language skills and understanding what they hear as well as difficulty in communicating their thoughts $[3,4]$. To express themselves, students with ASD exhibit unconventional behaviors such as being aggressive, throwing tantrums or injuring themselves [5]. However, their ability to communicate varies depending on their intellectual and social growth [6]. Thus, students with ASD are often recognized first by their social ineptness and communication failure.

During the playing time, students with ASD may keep to themselves instead of joining their peers [7,8]. In fact, students with ASD should be integrated with normal students in order to develop academic, social and emotional learning [9]. Sawitree [10] found that the learning of students with ASD is influenced by the development of social interaction with their peers. Furthermore, an important study done by Howlin \& Goode [11] has stated that students with ASD lack of social competencies, which is one of the important elements required in their future working environment and their quality of life.

Frith [12] further proposed that the social and communication deficits may impact academic performance including restricted interests, concrete and literal thinking, difficulties with solving problems, lack of organizational abilities, and having difficulty deciphering information. Teaching students with ASD in forming relationship and understanding the feelings of others are likely to be more important than academic learning as social skills is the greatest area of weakness among students with ASD [13,14]. Therefore, schools should take up the responsibilities to enhance the social skills among the students with ASD. However, many professionals believe that the schools do not play their part in catering the social and emotional needs of students with ASD [15].

In light of that, an appropriate educational programme is critical to students with ASD. Lovaas [16] and Smith [17] argued that students with ASD can benefit from a more typical educational setting if they are being provided with an appropriate educational and interventional experience in their young age. They need educational curriculum and programme that focus on improving numerous types of skills especially in their social skills [18]. To develop social skills, students with ASD need to have the opportunity to 
participate and interact in a variety of natural environments where appropriate model, natural cue and stimuli as well as functional reinforces are available. IE placement provides this access to peer models and social opportunities [19].

Inclusion among students with disabilities in the general classroom setting has become the international movement since the mid-to-late 1980s [20,21]. The students with ASD will benefit from the planned contact with their non-disabled peers in the same classroom [14]. With the implementation of the No Child Left Behind Act of 2001 and the reauthorization of IDEA in 1997 and 2004, the emphasis on educating students with ASD in the general education setting has increased dramatically [22].

Inclusive education (IE) is provided mainly based on all the children's right to access to high quality education alongside their peers regardless of their disability [23]. Since the last three decades, the concept of IE has been accepted [24]. There are many researches being done on the effects of IE towards students with learning disabilities [25]. Koegel et al. [26] proved that IE among disabled children will help them to improve in their social skills and perform better in their academic. According to Allen and Cowdery [27], Inclusive Education (IE) develops the children's social skills.

In line with the children's rights movement, Malaysia has taken its initiative to advocate special education in the Malaysian Education Act 1996 [28] for the children with SEN who have learning difficulty or disability that hinder them from making use of educational facilities provided in schools. Besides that, in the Education (Special Education) Regulations 2013 [29], the students with SEN will be provided with Special Education either in special schools or schools which implement Special Education Integrated Program (SEIP) or IE Program at all school levels.

Government of Malaysia has put in lots of effort to improve the quality of IE among the students with special needs. Based on the Salamanca Statement and Framework for Action on Special Needs Education [20] and the Persons with Disabilities (PWD) Act (2008) [30], Ministry of Education of Malaysia (MOE) set up its mission to give full and equal participation to those students with special needs in education as stated in National Education Blueprint (2013-2025) [31].

The latest research reported the prevalence of ASD has increased to 1 out of 64 [32]. Children with ASD are characterized by marked impairments in reciprocal social interaction, communication, and by repetitive and restricted interests and behaviours [33,34]. They will suffer throughout their lifetime [35]. As such, they are facing the greatest challenges to navigate to the social world.

Social skills are often described as a set of abilities that enable children to respond in acceptable ways to certain social requests [36]. There are three main areas of development, the triad of impairments: social interaction, communication and rigidity of behavior and thought, where people with ASD manifest differences [37].
Unchalee et al. [9] had identified the three problematic social skills among students with ASD: the self-control behavior, the communications skills and working in a team. However, students with ASD in IE will be difficult to succeed in school due to their limited social skills [38].

\section{A. Cognitive}

The largest predictor of outcome among the population of ASD is cognitive level [39]. Cognitive involves the ability to recognize and understand others' feelings [40]. Previous research have shown that children with ASD's significant symptoms such as poor social-emotional reciprocity and nonverbal communication skills impairments [41]. They are able to respond to others' emotions but they always fail to identify others' thoughts [42]. Besides that, they show impairments in theory of mind [43] and process facial expressions [44]. As mentioned above, children with ASD are having poor cognitive empathy $[45,46]$. Despite the deficits on cognitive ability, the researchers are also concern on other areas of social skills such as behavioral and affective.

\section{B. Behavioral}

Unchalee et al. [9] found that the students with ASD are lacking of communications skills in social interaction. They never greet, express appreciation and have eye contact during interaction and are unable to accept failure and work in a team with their peers too. Limsila [47] revealed that students with ASD always have one-way or being unusual during their interaction with others. The level of their social behavior is mostly lower than their age. They do not bother about the things or the people surrounded. Students with ASD find that it is difficult to join groups or make friends as they will not tell 'little white lies' and often cause offence without being aware [48].

\section{Affective}

Affective refers to emotional resonance which share others' feelings [40]. All three components of affective such as verbal responding, vocal intonation and facial expression are at the heart of the expression of emotion [49]. Deficits in affective among people with ASD will hinder them from responding appropriately for the initiation and maintaining social interaction with others [40]. Gena [51] stated that people with ASD give affective responses sometimes, but they do so non-contextually.

\section{Objectives}

There are two main objectives in this research. The first one is to identify the social skills deficits among students with ASD which involve three areas namely cognitive, behavioural and affective. The second objective is to determine the significant differences between the three areas in social skills among students with ASD in IE classrooms. 


\section{Materials and Methods}

The Social Skills Teacher Rating Form in TRIAD Social Skills Assessment (TSSA) has been used as instrument in this study by the participants to assess their students with ASD's social skills in IE classrooms. This is criterion-based instrument which assesses the students with ASD's knowledge and skills in three areas: (a) cognitive, (b) behavioral and (c) affective.

The cognitive area assesses the child's ability to understand other people's perspectives. Whereas, the behavioural aspect look into the child's ability to initiate and maintain interaction as well as respond appropriately to others. Finally, the affective element evaluates the child's ability to understand others' basic and complex emotions.

\subsection{Participants}

In this study, the informants consisted of 34 teachers of students with ASD in inclusive education classrooms in 3 government primary schools in Johor.

\subsection{Procedure}

Based on data obtained from Johor State Education Department (JPNJ), there are only 3 students with ASD being included in IE classrooms for Johor state. To carry out the data collection, researcher selected purposive sampling and approached the whole population of teachers who were involving in IE. The participants were given the informed consent form and a set of questionnaire to be filled in during their appointment with researcher. Researcher briefed them on the purpose and explained the items. Researcher collected the questionnaire and informed consent form right after the participants completed the task.

\subsection{Data Analysis}

Descriptive analyses method has been used to find out the mean of cognitive, behavioural and affective areas in the students with ASD's social skills. Besides that, repeated measures were used as inferential analyses to determine the significant differences among the three areas in social skills among students with ASD.

\section{Results \& Discussions}

\subsection{Descriptive}

Table 1 and Figure 1 showed that, on average, the participants reported relatively high level of knowledge and skills possessed by students with ASD in cognitive area $(\mathrm{M}=2.6324, \mathrm{SD}=0.67766)$. Whereas, students with ASD have the most observed social skills deficits fall under the areas of behavioral $(\mathrm{M}=2.2794, \mathrm{SD}=0.73021)$ and affective $(\mathrm{M}=2.3824, \mathrm{SD}=0.72883)$.
Table 1. Descriptive Statistics on Cognitive, Behavioral and Affective Areas in Social Skills among Students with ASD

\begin{tabular}{|c|c|c|c|}
\hline & Mean & Std. Deviation & $\mathrm{N}$ \\
\hline Cognitive & 2.6324 & .6777 & 34 \\
\hline Behavioral & 2.2794 & .7302 & 34 \\
\hline Affective & 2.3824 & .7288 & 34 \\
\hline
\end{tabular}

This findings related to the areas of social skills among students with ASD were partially consistent with [9] which showed that behavioral as one of the problematic social skills.

\subsection{Inferential}

Table 2. Mauchly's Test

\begin{tabular}{|c|c|c|c|c|}
\hline $\begin{array}{c}\text { Within Subjects } \\
\text { Effect }\end{array}$ & $\begin{array}{c}\text { Mauchly's } \\
\text { W }\end{array}$ & $\begin{array}{c}\text { Approx. } \\
\text { Chi-Square }\end{array}$ & df & Sig. \\
\hline Social Skills & .957 & 1.423 & 2 & .491 \\
\hline
\end{tabular}

Table 2 above indicated that Mauchly's test statistic is non-significant where $\chi^{2}(2)=1.42, p=.49$. It is then reasonable to conclude that the variances of differences between the three areas in social skills are not significantly different, meaning they are roughly equal. Thus, we can assume that the sphericity has been met.

Table 3. Tests of Within-Subjects Effects

\begin{tabular}{|c|c|c|c|}
\hline Source & & F & Sig. \\
\hline \multirow{3}{*}{ Social Skills } & Sphericity Assumed & 5.719 & .005 \\
\cline { 2 - 4 } & Greenhouse-Geisser & 5.719 & .006 \\
\cline { 2 - 4 } & Huynh-Feldt & 5.719 & .005 \\
\cline { 2 - 4 } & Lower-bound & 5.719 & .023 \\
\hline
\end{tabular}

From Table 3, one way repeated measure ANOVA using Greenhouse-Geisser criterion showed that there is a significant difference among the scores of three areas namely cognitive, behavioral and affective $(\mathrm{F}=5.719, \mathrm{P}=.006)$, which implied an unequibilirium in social skills among students with ASD.

Table 4. Pairwise Comparisons

\begin{tabular}{|c|c|c|c|c|}
\hline Social Skills & & Mean & Std. Deviation & Sig. \\
\hline \multirow{2}{*}{ Cognitive } & Behavioral & .353 & .096 & .002 \\
\cline { 2 - 5 } & Affective & .250 & .114 & .107 \\
\hline \multirow{2}{*}{ Behavioral } & Cognitive & -.353 & .096 & .002 \\
\cline { 2 - 5 } & Affective & -.103 & .111 & 1.000 \\
\hline \multirow{2}{*}{ Affective } & Cognitive & -.250 & .114 & .107 \\
\cline { 2 - 5 } & Behavioral & .103 & .111 & 1.000 \\
\hline
\end{tabular}

The results in Table 4 indicated that there is a difference between the three areas in social skills using Bonferroni for the post hoc tests. There is a significantly difference between cognitive and behavioral $(\mathrm{P}=.002<.05)$. 


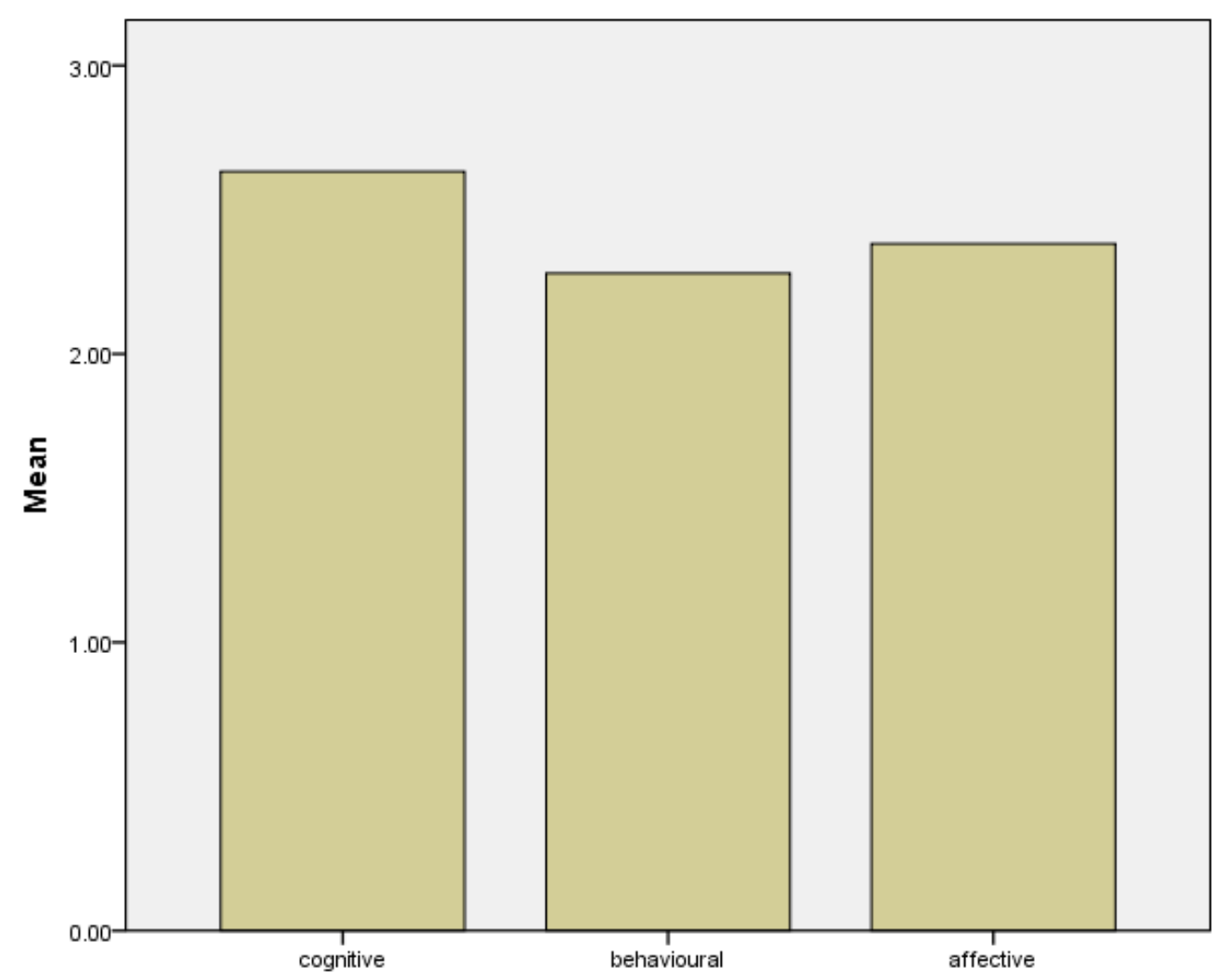

Figure 1. Areas of Social Skills Deficits of Children with ASD

\section{Discussion}

The Ministry of Health (MOH), Malaysia revealed that the prevalence figure of children with ASD is on the rise. In year $2012,6 \%$ of detected and registered special needs cases aged from 1-18 years old were autism as compared to $5 \%$ in year 2011 [52]. Due to high demands from the parents, Malaysia has started IE practices among students with ASD officially in Year 2005 under a collaboration effort between the Ministry of Education (MOE) and the National Autism Society of Malaysia [53]. However, the transformation of the education system has presented great challenges, specifically the mainstream teachers [54].

Based on a study which is being carried out by Zuri and Aznan [55], the result showed that approximately $68 \%$ of teachers have moderate and negative perceptions towards the implementation of IE. According to another local study conducted by Nornadia et al. [56], the findings showed that the teachers were not prepared to teach children with ASD in their classrooms as they were not familiar with the characteristics of children with ASD and did not understand the importance of IE. This finding resonates with the findings of Chhbra et al. [57] and De Boer et al. [58]. The factors which contributed to the negative attitudes among teachers included the type of disabilities of students, lacking of resources, support and professional training [58].

Nornadia et al. [56] stated that the awareness of the SEN among students with ASD in IE classrooms have been highlighted within the education field of Malaysia. Various courses and professional training are being conducted for teachers. Besides that, various researches have been carried out looking into the best teaching strategies for these included students with ASD.

Simpson [59] proposed that teachers need to be equipped with the basic management skills for mainstream and special education as well as special skills in relation to students with ASD in order to provide effective education to the students. According to Toran et al. [60], teachers need to understand the characteristics of their students with ASD.

Therefore, this study on social deficits has played its crucial role in IE practice of Malaysia. The empirical findings will be useful in helping to produce the effective teaching modules for students with ASD. Besides that, more systematic and well-planned teacher education and professional training can be provided to teachers based on the priority of SEN in the three aspects of social skills deficits, namely cognitive, behavioral and affective among students with ASD. With that, hopefully teachers in IE classrooms will be more confident and knowledgeable in managing the classrooms as well as yielding a more effective education outcome.

\section{Conclusions}

In short, children with ASD who are included will benefit in different ways and to different degrees on the three areas of social skills deficits namely behavioral, affective and cognitive in IE classrooms. In light of this, effective 
teaching as well as including students with ASD in the mainstream environment will always be a significant challenge for all professionals, parents, students with ASD and their peers $[61,62]$.

\section{Acknowledgements}

This work was supported in part by grant from the Ministry of Higher Education (MOHE), Fundamental Research Grant Scheme (FRGS) with the grant reference: PY/2014/03307 where the first author as the project manager.

\section{REFERENCES}

[1] American Psychiatric Association (APA). Diagnostic and Statistical Manual of Mental Disorders. (5th ed.) (DSM-V), American Psychiatric Association, Arlington, 2013.

[2] C. Schreiber. Social Skills Interventions for Children with High-Functioning Autism Spectrum Disorders, Journal of Positive Behavior Interventions, Vol.13, No.1, 49-62.

[3] T. Loucas, T. Charman, A. Pickles. Autistic symptomatology and language ability in autism spectrum disorder and specific language impairment, Journal of Child Psycho Psychiatry, Vol.49, 1184-1192.

[4] S. Mitchel, J. Brian, L. Zwaigenbaum, W. Roberts, P. Szatmari, I. Smith. Early language and communication development of infants later diagnosed with autism spectrum disorders, Journal of Developmental and Behavioral Pediatrics, Vol.27, S69-S78.

[5] A. M. Wetherby, J. Wood, I. Allen, J. Cleary, H. Dickson, C. Lord. Early indicators of Autism Spectrum Disorders in the second year of life, Journal of Autism and Developmental Disorders, Vol.34, No.5, 473-493.

[6] M. S. G. Josep, Q. Tan. Improving the process of inclusive in children with ASD in mainstream schools, Social and Behavioral Sciences, Vol.46, 4072-4076.

[7] U. Trangkasombat. Helping An Autistic Child, Handbook for Father and Mother Who Never Gives Up, Bangkok: Research Center and Family Development Company Limited, 2002.

[8] P. Jewpatanakul. Development of Exercises to Enhance Social Skills for Autistic Children, Theses towards the Doctorate Degree of Education in Special Education Instruction, Graduate School, Srinakharinwirot University, 2006.

[9] S. Unchalee, M. Thidakorn, S. Kamonrat. Social Skills Deficits of Students with Autism in Inclusive Schools, Social and Behavioral Sciences. Vol.116, 509-512.

[10] R. Sawitree. The development of social interaction of children with autism in inclusive classrooms, Social and Behavioral Science, Vol.116, 4108-4113.

[11] P. Howlin, S. Goode. Outcome in Adult Life for People with Autism, Asperger Syndrome. In F. R. Volkmar (Eds.), Autism and Pervasive Developmental Disorders (pp.209-241),
New York: Cambridge University Press, 1998.

[12] U. Frith. Autism and Asperger Syndrome, Cambridge University Press, New York, 1991.

[13] F. M. Gresham. Social Skill Training with Children: Social Learning and Applied Behavioral Analytic Approaches. In T. S. Watson \& F. M. Gresham (Eds.), Handbook of Child Behavior Therapy (pp.475-497), New York: Plenum Press, 1998.

[14] J. B. Kupersmidt, M. E. DeRosier. How Peer Problems Led to Negative Outcomes: An Integrative Mediational Model. In J. B. Kupersmidt \& K.A. Dodge (Eds.), Children's Peer Relations: From Development to Intervention (pp.119-138), Washington: American Psychological Association, 2004.

[15] S. Bryson, S. Rogers, E. Fombonne, Autism spectrum disorders: early detection, intervention, education, and psychopharmacological management, Online available from http://www.cpa-apc.org/Publications/Archives/CJP/2003/sep tember/bryson.asp

[16] O. I. Lovaas. Behavioral treatment and normal educational and intellectual functioning in young autistic children, Journal of Consulting and Clinical Psychology, Vol.55, 3-9.

[17] T. Smith, A. D. Groen, J. W. Wynn. Randomized trial of intensive early intervention for children with pervasive developmental disorder, American Journal on Mental Retardation, Vol.105, 269-285.

[18] S. K. William, C. Johnson, D. G. Sukhodolsky. The role of the school psychologist in the inclusive education of school-age children with autism spectrum disorders, Journal of School Psychology, Vol.43, 117-136.

[19] R. Pierangelo, G. Giuliani. Teaching Students with Autism Spectrum Disorders, Corwin Press, Carlifornia, 2008.

[20] UNESCO. Access and Quality, World Conference on Special Needs Education, Salamanca, 1994.

[21] UNESCO. Salamanca-five years on: A review of UNESCO activities in the light of the Salamanca Statement and Framework for Action on Special Needs Education, Paris, 1999.

[22] M. L. Yell, A. Katsiyannis, E. Dragsow, M. Herbst. Developing Legally Correct and Educationally Appropriate Programs for Students with Autism Spectrum Disorders, Focus on Autism \& other Developmental Disabilities, Vol.18, No.3, 182-192.

[23] S. Shahzadi. Inclusive Education: Perspective of Service, International Special Education Congress 2000, University of Manchester, 234-239, 2000.

[24] T. Heiman. Teachers Coping with Changes: Including Students with Disabilities in Mainstream Classes: An International View, International Journal of Special Education, Vol.19, No.2, 91-103.

[25] S. Biddle. Attitudes in Education: Assessing How Teachers' Attitudes about Inclusion of Learning Disabled Students Affects Their Use of Accommodations, The Science Teacher, Vol. 73, No.3, 52-56.

[26] L. Koegel, R. M. Fredeen, R. Lang, R. Koegel. Interventions of Children with Autism Spectrum Disorders in Inclusive School Settings. Cognitive and Behavioral Practice, 2011. 
[27] K. E. Allen, G. E. Cowdery. The Exceptional Child: Inclusion in Early Childhood Education, Thomson Delmar Learning, 2005

[28] Education Act 1996, (Act 550) Part IV, National Education System. Chap. 8, International Law Book Services, Kuala Lumpur, 1998.

[29] Government of Malaysia, P.U. [A]. 230, Education (Special Education) Regulations 2013, Kuala Lumpur, 2013.

[30] Government of Malaysia, Law of Malaysia, Act 685, Persons with Disabilities Act 2008, Kuala Lumpur, 2008.

[31] Ministry of Education (MOE), National Education Blueprint (2013-2025), Malaysian Ministry of Education, Putrajaya, 2013.

[32] M. Ganz, The Costs of Autism. In Understanding Autism: From Basic Neuroscience to Treatment, Online available from http://dx.doi.org/10.1201/9781420004205.ch20

[33] American Psychiatric Association (APA). Diagnostic and Statistical Manual of Mental Disorders. (4 ${ }^{\text {th }}$ ed.) (DSM-IV), American Psychiatric Association, Arlington, 2000.

[34] WHO. The ICD-10 Classification of Mental and Behavioral Disorders: Clinical Descriptions and Diagnostic Guidelines, Geneva, 1992.

[35] M. R. Nornadia, T. Hasnah, K. Sazlina, M. S. Norshidah, M. S., M. Y. Mohd Hanafi. Teachers' Perceptions of Including Children with Autism in a Preschool, Asian Social Science. Vol.9, No.12, 261-267.

[36] S. N. Elliott, D. N. Mckinnie. Relationships and Differences among Social Skills, Problem Behavior, and Academic competence for mainstreamed learning-disabled and Non-handicapped students, Canadian Journal of School Psychology, Vol.10, 1-14.

[37] L. Wing. The Continuum of Autistic Characteristics, in Schopler, E. and Mesibow, G (eds) Diagnosis and assessment in autism, Plenum Press, New York, 1988.

[38] D. Uthairattanakit. Helping an Autistic Child, Handbook for Father and Mother Who Never Gives Up, Research Center and Family Development Company Limited, Bangkok, 2002.

[39] A. Levy, A. Perry. Outcomes in Adolescents and Adults with Autism: A Review of the Literature, Research in Autism Spectrum Disorders, Vol.5, 1271-1282.

[40] J. Decety. Dissecting the Neural Mechanism Mediating Empathy, Emotion Review, Vol.3, 92-108.

[41] D. Bons, E. Van Den Broek, F.Scheepers, P. Herpers, N. Rommelse, J. K. Buitelaaar. Motor, emotional, and cognitive empathy in children and adolescents with autism spectrum disorder and conduct disorder, Journal of AbnormalChild Psychology, Vol.41, 425-443.

[42] S. Baron-Chen, H. Tager-Flusberg, D. J. Cohen. Understanding Other Minds: Perspectives from Autism, Oxford University Press, Oxford, 1993.

[43] E. L. Hill, U. Frith. Understanding Autism: Insights from Mind and Brain. Philosophical Transactions of the Royal Society B: Biological Sciences, Vol.358, 281-289.

[44] M. B. Harms, A. Martin, G. L. Wallace. Facial Emotion
Recognition in Autism Spectrum Disorders: A Review of Behavioral and Neuroimaging studies, Neuropsychology Review, Vol.20, 290-322.

[45] A. P. Jones, F. G. E. Happe, F. Gilbert, S. Burnett, E. Viding. Feeling, caring, knowing: Different types of empathy deficit in boys with psychopathic tendencies and autism spectrum disorder, Journal of Child Psychology and Psychiatry, Vol.51, 1188-1197.

[46] C. Schwenck, J. Merganthaler, K. Keller, J. Zech, S. Salehi, R. Taurines. Empathy in children with autism and conduct disorder: Group-specific profiles and developmental aspects, Journal of Child Psychology and Psychiatry, Vol.53, 651-659.

[47] P. Limsila. Teachers, Physicians, Parents: Dimensions for Autistic Person's Potentiality Development, Autism in Thailand: From Textbook into Experience, International Academic Conference, Kasetsat University, 2002.

[48] L. Primley, M. Bowen. Social Skills and Autistic Spectrum Disorders, Paul Chapman Publishing, London, 2007.

[49] N. Daou, S. M. Vener, C. L. Poulson, C. L. Analysis of Three Components of Affective Behavior in Children with Autism. Research in Autism Spectrum Disorders, Vol.8, No.5, 480-501.

[50] R. J. Gaylord-Ross, T. C. Haring, C. Breen, V. Pitts-Conway. The Training and Generalization of Social Interaction Skills with Autistic Youth, Journal of Applied Behavior Analysis, Vol.17, 229-247.

[51] A. Gena. Training and Generalization of Affective Behavior Displayed by Youth with Autism, City University of New York, New York, 1994.

[52] Government of Malaysia, Children with Disabilities in Malaysia: Mapping the Policies, Programmes, Interventions and Stakeholders, Kuala Lumpur, 2013.

[53] M. S. Bong. Education for children with autism in Malaysia., Online available from http://www.nise.go.jp/kenshuka/josa/kankobutsu/pub_d/d-29 2/d-292_16.pdf

[54] H. Sufean, A. H. Quek, S. C. Loh. Policy into practice: The challenge for special education in Malaysia, $11^{\text {th }}$ International Conference on Experiential Learning, Sydney, 8-12 December, 2008.

[55] M. Zuri Ghani, C. A. Aznan, Teachers' perceptions towards the implementation of inclusive education in Penang, Malaysia, PERTANIKA Journal of Social Science and Humanities, Vol.20, No.4, 961-972.

[56] M. R. Nornadia, T. Hasnah, K. Sazlina, M. S. Norshidah, M. Y. Mohd. Hanafi, Teachers' perceptions of including children with autism in a preschool, Asian Social Science, Vol.9, No.12, 261-267.

[57] S. Chhabra, R. Srivastava, I. Srivastava, Inclusive education in Botswana: The perceptions of school teachers, Journal of Disability Policy Studies, Vol.20, No.4, 219-228.

[58] A. De Boer, S. J. Pijl, A. Minnaert. Regular primary school teachers' attitudes towards inclusive education: A review of the literature, International Journal of Inclusive Education, Vol.15, No.3, 331-353. 
[59] R. L. Simpson, Finding effective intervention and personnel preparation practices for students with autism spectrum disorders, Exceptional Children, Vol.20, No.2, 135-144.

[60] H. Toran, M. Y. Mohd. Hanafi, T. Mohd. Mokhtar, S. Norani, Level of training, knowledge and confidence of special need teachers on autism, Malaysian Journal of Education, Vol.31, No.1, 19-26.
[61] M. S. G. Josep, Q. Tan. Improving the Process of Inclusive Education in Children with ASD in Mainstream Schools. Social and Behavioral Sciences, Vol.46, 4072-4076.

[62] D. L. Ennis-Cole. Technologies for Learners with Autism Spectrum Disorders, Springer International Publishing, Switzerland, 2015. 